\title{
Desempenho das Exportações do Pólo Petrolina-Juazeiro: Análise comparativa dos resultados da Balança Comercial
}

\author{
Liliane Caraciolo Ferreira $^{1}$; Henrique Bruno Barros de Souza ${ }^{2}$;Joelma Patricia Pimenta de Santana ${ }^{3}$
}

\begin{abstract}
Resumo: Este artigo objetivou a realização de uma análise comparativa dos resultados obtidos pela balança comercial do pólo Petrolina-Juazeiro no período compreendido entre 2000 a 2015. Localizado no submédio do São Francisco, tendo a fruticultura irrigada como principal fonte de atividade econômica, transformou-se no maior exportador de frutas do Brasil. A procura pelas frutas produzidas na região, principalmente uvas e mangas, vem crescendo a cada ano, tornando a exportação uma estratégia de geração de riquezas e rendas. Foram realizadas, também, abordagens teóricas sobre exportação, importação e balança comercial. Com base nos resultados obtidos através de dados do MDIC, foi evidenciado o crescimento econômico nos últimos 15 anos no referido pólo e sua devida importância para a balança comercial e, por conseguinte, para o desenvolvimento do pólo.
\end{abstract}

Palavras-chave: fruticultura, comércio exterior, crescimento econômico.

\section{Performance of Petrolina-Juazeiro Export: Comparative analysis of the results of the trade balance}

\begin{abstract}
This paper aimed to conduct a comparative analysis of the results in the trade balance of PetrolinaJuazeiro pole in the period from 2000 to 2015 . Located in the sub-middle of the São Francisco river, with irrigated orcharding as the main source of economic activity, this pole turned into the largest exporter of fruit in Brazil. The demand for fruits produced in the region, mainly grapes and mangoes, is growing every year, making the exportation a strategy for generating wealth and income. Theoretical approaches were held on export, import and trade balance. Based on the results obtained through MDIC data, it was evident the economic growth in the last 15 years in that pole, its due importance to the trade balance and, therefore, for the development of the pole.
\end{abstract}

Keywords: fruit production, foreign trade, economic growth.

\footnotetext{
${ }^{1}$ Possui graduação em Economia (UFPE), mestrado em Administração Rural (UFRPE) e doutorado em Psicologia, na área de Psicologia Social (UFES), e-mail: liliane.ferreira@univasf.edu.br.

${ }^{2}$ Pós-graduando em Gestão Pública pela Universidade Federal do Vale do São Francisco e graduado em Administração de Empresas pela Universidade Federal do Vale do São Francisco, Petrolina-Pe, e-mail: henrique.bbsouza@ gmail.com.

${ }^{3 P}$ ós-graduanda em Gestão Pública pela Universidade Federal do Vale do São Francisco e graduada em Administração de Empresas pela Universidade Católica do Salvador, Salvador-BA, e-mail: joelmapatricia@hotmail.com.
} 
Id on Line Revista Multidisciplinar e de Psicoloqia

Id on Line Multidisciplinary Journal and Psycology

\section{Introdução}

Considerando que o comércio exterior passou a constituir ao longo dos anos, principalmente a partir do início dos anos 90, uma importante fonte de receitas para os exportadores brasileiros, bem como de profissionalização das empresas brasileiras com vistas a acompanhar as normas e padrões de qualidade do comércio internacional, pode-se reconhecer o salto de qualidade obtido pelo mercado interno desde que foram intensificadas negociações políticas para a abertura comercial do Brasil.

A expansão dos negócios realçou a necessidade das empresas brasileiras tornarem-se competitivas internacionalmente, devido a ampliação dos mercados consumidores, através do acesso a novas tecnologias e processos mais modernos. O comércio exterior permite a geração de empregos, elevação de rendas, tanto no curto quanto no longo prazo, contribuindo para o desenvolvimento econômico e melhoria dos indicadores sociais.

Vale lembrar, também, que as transações comerciais entre os países têm importantes funções econômicas, pois abastece os mercados com produtos de que necessitam os consumidores, contribui para o desenvolvimento da produção e do consumo, estimula a expansão dos meios de transporte e comunicação, estabelece o intercâmbio cultural entre as diferentes comunidades, entre outros. Tudo isso contribui para a dinamização do desenvolvimento de um país e, sem dúvidas, de uma região específica.

Complementando a visão da abertura comercial, segundo Vieira (2008, p. 60) "as exportações desempenham papel fundamental no comércio internacional de um país, pois dinamizam o processo de desenvolvimento econômico e social".

Conforme a relevância do assunto supracitado, este artigo tem o objetivo de analisar o desempenho das exportações do pólo Petrolina-Juazeiro, grande exportador de frutas do Brasil, em especial uvas e mangas, a partir dos resultados da balança comercial brasileira, fazendo uma análise comparativa dos resultados obtidos nos últimos anos. Serão explanados conceitos de exportação, importação, balança comercial, bem como apresentado o pólo Petrolina-Juazeiro.

\section{Metódos}

A metodologia utilizada baseou-se em Sobel e Ortega (2007), utilizando informações dos municípios do pólo Petrolina-Juazeiro através da criação de um grupo dos municípios próximos ao pólo, chamado de grupo I, excluindo-se os municípios de Petrolina e Juazeiro que foram tratados isoladamente pela representatividade das informações. O Grupo Outros, segundo Sobel e Ortega 
Id on Line Revista Multidisciplinar e de Psicoloqia

Id on Line Multidisciplinary Journal and Psycology

(2007, p. 3) contempla os municípios de: "Santa Maria da Boa Vista, Lagoa Grande e Orocó, pelo lado pernambucano; e Casa Nova, Curaçá e Sobradinho, pelo lado baiano". Os resultados foram obtidos a partir de dados oficiais do Ministério do Desenvolvimento, Indústria e Comércio Exterior (MDIC) a respeito da balança comercial desta microrregião, analisando os resultados dos anos 2000, 2005, 2010 e 2015.

\section{Exportação}

Antes de explanar sobre os conceitos da exportação, torna-se imprescindível destacar a importância da internacionalização das empresas e, por conseguinte, da exportação. A interação das empresas com os mercados globalizados, através da abertura comercial, torna-se uma importante estratégia, tendo em vista possibilitar as condições de integração produtiva das empresas, permitindo aprimoramento dos seus métodos administrativos e organizacionais, desenvolvimento de nova cultura, aumento nos ganhos de escala e rompimento de barreiras comerciais (LOPEZ; GAMA, 2010, p.31).

Isto porque, conforme Lopez e Gama (2010, p. 31) "a adequação do produto ao mercado consumidor vai produzindo na empresa uma mudança de mentalidade que termina por propiciar um salto qualitativo". Ou seja, a abertura das empresas ao comércio exterior imprime responsabilidades com reflexos positivos, inclusive, no mercado interno. Ela passa a reinventar suas estratégias mercadológicas, assimilar novas técnicas de produção e comercialização.

De acordo com Lopez e Gama (2010, p. 31) "exportar é uma alternativa estratégica de desenvolvimento, na medida em que estimula a eficiência".

Exportar, conforme Lopez e Gama (2010, p. 215): “exportação de uma mercadoria se configura quando ela é disponibilizada ao comprador estrangeiro em local e prazo estipulados em contrato de compra e venda internacional."

$\mathrm{Ou}$ seja, trata-se do envio de produtos produzidos nacionalmente para um mercado consumidor externo. Ainda conforme Lopez e Gama (2010, p. 215) "a exportação ocorre com a saída da mercadoria do território aduaneiro, que compreende todo o território nacional".

A afirmação de que houve exportação varia em função do modal de transporte utilizado, pois o modal terrestre considera quando do cruzamento da fronteira, já os modais aéreo e marítimo consideram o momento de ingresso no veículo de transporte internacional. Além disso, a jurisdição dos serviços aduaneiros considera duas zonas: a primaria corresponde as áreas ocupadas pelos portos, aeroportos e áreas adjacentes aos pontos de fronteira; a secundária equivale ao restante do território, incluindo as águas territoriais e o espaço aéreo (LOPEZ; GAMA, 2010, p. 215). 
Id on Line Revista Multidisciplinar e de Psicoloqia

Id on Line Multidisciplinary Journal and Psycology

As exportações dividem-se em dois tipos: direta e indireta. As exportações diretas ocorrem quando o exportador realiza uma venda direta a um comprador localizado em outro país, requerendo grande conhecimento por parte do exportador acerca dos riscos e custos envolvidos no processo de exportação. As exportações indiretas envolvem um comprador interno do produto e futuro vendedor ao mercado externo, portanto realizador, de fato, da exportação. Geralmente, existem empresas tipicamente exportadoras, cooperativas ou consórcios de exportação, entre outros. Na verdade, trata-se de intermediação de todo o processo devido ao conhecimento e experiência no comércio internacional (LOPEZ; GAMA, 2010, p. 216).

\section{Importação}

A importação representa segundo Lopez e Gama (2010, p. 303) “a entrada de mercadoria em um país, procedente do exterior. Perante a legislação brasileira, a importação se configura no momento do desembaraço aduaneiro". Ou seja, a confirmação da importação ocorreria após a transferência de propriedade dentro do território nacional.

No entanto, de acordo com o direito internacional, a transferência de propriedade se realiza com o recebimento da mercadoria, considerando as cláusulas existentes no contrato de compra e venda, no exterior pelo comprador ou seu representante (LOPEZ; GAMA, 2010, p. 303).

É importante frisar que para configurar como grande exportador de produtos, um país necessita importar materiais os quais não são produzidos em seu território, como matérias-primas, insumos, produtos intermediários, máquinas e equipamentos, entre outros. Trata-se de estabelecer uma relação de trocas entre países com entrada de mercadorias e saída de divisas. Da mesma forma, permite que produtos estrangeiros possam competir com os nacionais, permitindo a criação de uma concorrência saudável e estabilizando preços e estoques. (SOUZA, 2003, p. 143).

Reiterando as afirmações anteriores, conforme Souza (2003, p. 144) "o comércio exterior funciona como uma via de mão dupla, ou seja, deve haver uma reciprocidade entre os países que estão negociando suas mercadorias e produtos". Deve-se entender que o fato de importar tecnologias estrangeiras, além de máquinas e equipamento, permite um ambiente de melhoria contínua nos processos produtivos, criando oportunidades de bons negócios no mercado internacional e, por sua vez, gerando bons resultados na balança comercial de um país (SOUZA, 2003, p. 144). 
Id on Line Revista Multidisciplinar e de Psicoloqia

Id on Line Multidisciplinary Journal and Psycology

\section{Balança Comercial}

Com o propósito de explanar a respeito da balança comercial, é fundamental entender, também, o balanço de pagamentos.

De acordo com Dornbusch e Fischer (1991, p. 204) "O balanço de pagamentos é o registro das transações dos residentes de um país com o resto do mundo". Ainda conforme Dornbusch e Fischer (1991, p. 204) "Existem duas contas principais no balanço de pagamentos: conta corrente e conta capital".

A conta corrente tem em seu cerne o registro das transações comerciais de bens e serviços, bem como o pagamento de transferências. As exportações e importações estão incluídas nesta conta, ou seja, contabilizam quanto um país comprou de produtos estrangeiros e quanto de produtos nacionais foram vendidos no mercado internacional. As transferência correspondem aos pagamentos privados e públicos entre os países. Geralmente, estas transferências correspondem a pagamentos de pensões ou auxílios (FROYEN, 2002, p. 540).

A conta capital corresponde à compra de ativos domésticos ou estrangeiros, gerando um saldo a partir destas transações. Conforme Froyen (2002, p. 540) "entradas de capital incluem compras por estrangeiros de títulos privados ou governamentais, ações e depósitos bancários domésticos". Investimentos estrangeiros diretos no país também são considerados entradas de capital e, portanto, ingressam como crédito. Seguindo a lógica, de Froyen (2002, p. 541) "compras de ativos financeiros ou investimentos diretos em países estrangeiros realizados por residentes são saídas de capital”.

A respeito da balança comercial, pode-se afirmar que a mesma encontra-se dentro da conta corrente do balanço de pagamentos, sendo calculada pela diferença entre as exportações e as importações, nesta sequência. Saldo, este, relativo ao comércio de bens e serviços. (FROYEN, 2002, p. 539)

A balança comercial, também conhecida como exportações líquidas, traz informações a respeito do quanto um país exporta dos seus bens e serviços e do quanto que ele importa de outros países. O valor positivo obtido na balança comercial indica superávit comercial, ou seja, o país exportou a produção excedente (pode-se afirmar que a produção excedeu o gasto interno). $\mathrm{O}$ saldo negativo da balança constitui déficit comercial, portanto, o país importou mais produtos do que exportou (pode-se dizer que o gasto interno superou a produção). A balança equilibrada significa valor igual das exportações e importações de uma economia (MANKIW, 2010, p. 94-96). 
Id on Line Revista Multidisciplinar e de Psicoloqia

Id on Line Multidisciplinary Journal and Psycology

\section{Pólo Petrolina-Juazeiro}

O pólo Petrolina-Juazeiro está localizado no semiárido brasileiro, às margens submédio do Rio São Francisco, no extremo oeste de Pernambuco e norte da Bahia, sendo composto pelos seguintes municípios: Lagoa Grande, Orocó, Petrolina, Santa Maria da Boa Vista, no Estado de Pernambuco, e pelos municípios de Casa Nova, Curaçá, Juazeiro e Sobradinho, no Estado da Bahia, conforme figura 01 a seguir.

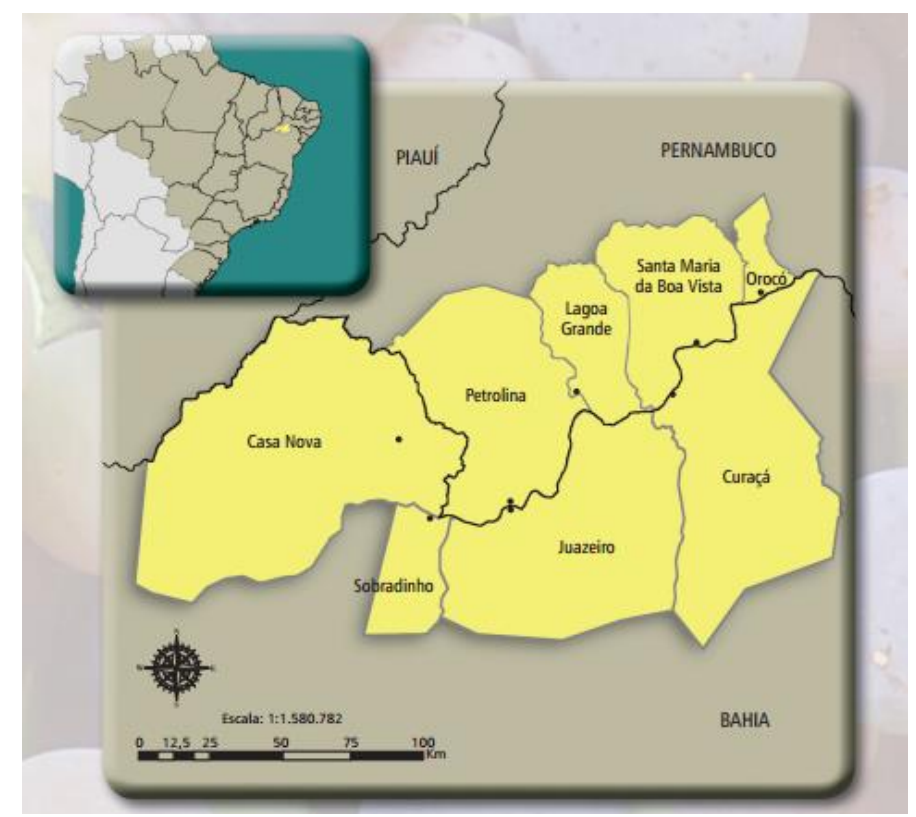

FIGURA 01 - Municípios do Pólo Petrolina-Juazeiro

Fonte: Região Integrada de Desenvolvimento Econômico (RIDE) - Ministério da Integração Nacional (2016).

A fruticultura irrigada no referido pólo tem se mostrado bastante evoluída, com ênfase no crescimento de produção e exportação no cenário da economia mundial e nacional de frutas como manga e uva de qualidade, se adequando não somente ao mercado interno como também aos consumidores internacionais por suas exigências peculiares pelo destino das frutas exportadas. Esta contribuição eleva o alto desenvolvimento econômico da região fazendo com que haja uma grande parcela de contribuição para o crescimento do PIB dessa região.

Segundo Falcade (2005), no final da década de 60, investimentos foram possíveis graças à implantação de projetos públicos e privados em favor da fruticultura irrigada na região, tornando-se a sua principal atividade econômica.

Esses investimentos favoreceram aos produtores, fazendo assim a expansão de sua rede para o mercado externo e produzindo também impactos significativos sobre a renda e emprego do pólo. A garantia do sucesso de produção deve-se ao clima da região, predominantemente quente e seco em 
Id on Line Revista Multidisciplinar e de Psicoloqia

Id on Line Multidisciplinary Journal and Psycology

quase toda parte do ano, e a infraestrutura de irrigação e mão de obra disponível. Assim, obtêm-se frutas de melhor qualidade na regularidade de produção e consegue-se competir em ótimas condições no mercado internacional (BUAINAIN; BATALHA, 2007).

\section{Resultados}

Após análise da balança comercial do pólo Petrolina-Juazeiro no site do MDIC, a partir da base de dados dos municípios, obteve-se os seguintes resultados no comparativo dos anos 2000, 2005, 2010 e 2015, em dólar comercial americano.

\begin{tabular}{|ccccc|}
\hline Localidade & 2000 & 2005 & 2010 & 2015 \\
Petrolina & $\$ 22.553 .844,00$ & $\$ 82.102 .990,00$ & $\$ 128.168 .641,00$ & $\$ 170.756 .109,00$ \\
Juazeiro & $\$ 30.969 .394,00$ & $\$ 53.943 .523,00$ & $\$ 66.700 .412,00$ & $\$ 52.193 .032,00$ \\
Outros & $\$ 4.042 .491,00$ & $\$ 34.521 .807,00$ & $\$ 67.746 .745,00$ & $\$ 60.859 .121,00$ \\
Total & $\$ 57.565 .729,00$ & $\$ 170.568 .320,00$ & $\$ 262.615 .798,00$ & $\$ 283.808 .262,00$ \\
\hline
\end{tabular}

TABELA 01 - Exportações do Pólo Petrolina-Juazeiro

Fonte: Balança Comercial Brasileira por Município - MDIC (2016).

\begin{tabular}{|cclll|}
\hline Localidade & \multicolumn{1}{c}{2000} & \multicolumn{1}{c}{2005} & \multicolumn{1}{c|}{2010} & \multicolumn{1}{c|}{2015} \\
Petrolina & $\$ 2.509 .937,00$ & $\$ 5.183 .659,00$ & $\$ 119.463 .264,00$ & $\$ 17.293 .419,00$ \\
Juazeiro & $\$ 2.242 .853,00$ & $\$ 4.917 .284,00$ & $\$ 9.868 .289,00$ & $\$ 9.984 .211,00$ \\
Outros & $\$ 177.074,00$ & $\$ 633.196,00$ & $\$ 2.865 .253,00$ & $\$ 2.811 .806,00$ \\
Total & $\$ 4.929 .864,00$ & $\$ 10.734 .139,00$ & $\$ 132.196 .806,00$ & $\$ 30.089 .436,00$ \\
\hline
\end{tabular}

TABELA 02 - Importações do Pólo Petrolina-Juazeiro

Fonte: Balança Comercial Brasileira por Município - MDIC (2016).

\begin{tabular}{|c|c|c|c|c|}
\hline Localidade & 2000 & 2005 & 2010 & 2015 \\
\hline Petrolina & $\$ 20.043 .907,00$ & $\$ 76.919 .331,00$ & $\$ 8.705 .377,00$ & $\$ 153.462 .690,00$ \\
\hline Juazeiro & $\$ 28.726 .541,00$ & $\$ 49.026 .239,00$ & $\$ 56.832 .123,00$ & $\$ 42.208 .821,00$ \\
\hline Outros & $\$ 3.865 .417,00$ & $\$ 33.888 .611,00$ & $\$ 64.881 .492,00$ & $\$ 58.047 .315,00$ \\
\hline Total & $\$ 52.635 .865,00$ & $\$ 159.834 .181,00$ & $\$ 130.418 .992,00$ & $\$ 253.718 .826,00$ \\
\hline
\end{tabular}

TABELA 03 - Balança Comercial do Pólo Petrolina-Juazeiro.

Fonte: Balança Comercial Brasileira por Município - MDIC (2016). 
Id on Line Revista Multidisciplinar e de Psicoloqia

Id on Line Multidisciplinary Journal and Psycology

\section{Discussões}

Com base nos resultados elencados em tópico anterior, verificou-se o crescimento alcançado pelo pólo Petrolina-Juazeiro nos últimos 15 anos, representando crescimento no superávit da balança comercial de aproximadamente 380\%, quando comparados os anos 2000 e 2015. É notório observar que, diante do quadro de aumento do dólar no ano de 2015, pode-se afirmar que o superávit comercial esteve próximo de 1 bilhão de reais, mostrando a força das exportações para a economia local em termos de geração de riquezas, emprego e renda, competitividade no mercado externo, entre outros.

Além disso, a cidade de Petrolina-PE liderou com folga as exportações de 2015, alcançando um valor maior que a soma de Juazeiro-BA e dos outros municípios. Em relação a Juazeiro-Ba, observou-se que desde 2010 perdeu o segundo lugar nas exportações para os municípios do Grupo Outros, liderados por Casa Nova-BA e Lagoa Grande-PE.

Conforme MDIC (2016), o principal destino das exportações do pólo são os Países Baixos (Holanda), liderando desde os anos 2000 em valores bem maiores que os demais países. Outros países como Estados Unidos, Reino Unido, Espanha, Portugal, França figuram com destaque em valores exportados e em continuidade ao longo dos últimos anos, com variações. A Argelia aparece como segundo maior destino das exportações de Petrolina-PE no ano de 2015, sendo um novo mercado a ser explorado.

Com relação aos blocos econômicos, segundo informações do MDIC (2016), os principais destinos nos últimos 15 anos são a União Europeia e os Estados Unidos (inclusive Porto Rico), porém a África e a Ásia apresentam crescimento desde 2010. O Mercosul também figura entre os blocos exportados, no entanto, muito aquém diante dos acordo comerciais envolvendo os países do bloco. Apenas a Argentina apresenta valor considerável nas exportações do pólo, porém bem abaixo dos demais países já citados.

Já os principais produtos, de acordo com MDIC (2016) exportados ao longo dos últimos 15 anos são uvas e mangas, em torno de $80 \%$, demonstrando que a maioria das exportações é de produtos primários, de bens não duráveis. Melões, mamões, limões, sumos de frutas e abacaxis também fazem parte dos produtos exportados pelo pólo, no entanto, com valores bem abaixo. Um fato observado nas exportações de Petrolina-PE é a presença no ano de 2015 de \$ 55 milhões de dólares de bens intermediários, a saber: óleo de soja, tortas e outros resíduos de óleo de soja, fazendo com que novos mercados possam surgir e a dependência da exportação de produtos primários seja coordenada com novas tendências e estudos da região. No ano de 2010, cinco anos atrás, não houve exportação destes produtos. 
Id on Line Revista Multidisciplinar e de Psicoloqia

Id on Line Multidisciplinary Journal and Psycology

\section{Conclusões}

Schuh (1989) revela que saldos positivos na balança comercial remetem-se ao excelente rendimento do setor agrícola, nesse caso está relacionado até certo ponto, num melhor ordenamento de renda e continuidade do crescimento econômico.

Após análise dos resultados, o pólo Petrolina-Juazeiro sofreu nos últimos 15 anos transformações importantes no setor de exportação de frutas, valendo o destaque especialmente a Petrolina, que supera a cada dia Juazeiro nas exportações apresentadas, gerando impactos positivos na infraestrutura e crescimento econômico da cidade, fato de grande relevância pela presença de investidores externos e parcerias entre os produtores, prefeitura e órgãos públicos.

De fato, as projeções aqui realizadas da balança comercial para o período 2005 a 2015 , sugerem que a cada dia será crescente a trajetória da balança, sendo observado que desde o primeiro período analisado, a fruticultura irrigada ganhou uma grande importância na economia da região. Através dos consecutivos aumentos das exportações, bem como nos sucessivos superávits na balança comercial chegando próximo de 1 bilhão de reais, evidencia-se o apoio à economia local, lembrando que esse desempenho sempre é apoiado nas vantagens climáticas, incorporação de novas tecnologias e elevada força em atrair representantes comerciais com experiência no comércio exterior.

Entre os períodos estudados, a participação do pólo na exportação nacional de uva e manga mantém-se em crescimento, sendo destaque no âmbito nacional.

\section{Referências}

BUAINAIN, Antonio Márcio et al. (Ed.). Cadeia produtiva de frutas. Bib. Orton IICA/CATIE, 2007.

DORNBUSCH, Rudiger; FISCHER, Stanley. Macroeconomia. 5 ed. Tradução e revisão técnica Roberto Luis Troster. São Paulo: Pearson Makron Books, 1991.

FALCADE, Ivanira. Paisagens vitícolas brasileiras. In: X Congresso Brasileiro de Viticultura e Enologia. Bento Gonçalves: 2005.

FROYEN, Richard T. Macroeconomia. Tradução de Esther E. H. Herskovitz, Cecilia C. Bartalotti. Revisão técnica de Roland Veras Saldanha Jr. São Paulo: Saraiva, 2002.

LOPEZ, José Manoel Cortinãs; GAMA, Marilza. Comércio Exterior Competitivo. 4. ed. São Paulo: Aduaneiras, 2010.

MANKIW, N. Gregory. Macroeconomia. Tradução e revisão técnica Teresa Cristina Padilha de Souza. Rio de Janeiro: LTC, 2010. 


\section{MINISTÉRIO DO DESENVOLVIMENTO, INDÚSTRIA E COMÉRCIO EXTERIOR - MDIC. Balança Comercial Brasileira por Município. Disponível em:} http://www.desenvolvimento.gov.br//sitio/sistema/balanca/. Acesso em: 19 abr. 2016.

REGIÃO INTEGRADA DE DESENVOLVIMENTO ECONÔMICO - RIDE. Disponível em: http://www.mi.gov.br/regiao-integrada-de desenvolvimento-do-polo-petrolina-e-juazeiro. Acesso em: 15 fev. 2016.

SCHUH, G. E. Política agrícola numa economia internacional bem integrada: o caso do Brasil. Revista de Economia e Sociologia Rural, v.27, n.2, p.107-124, abr./jun. 1989.

SOBEL, Tiago Farias; ORTEGA, Antônio César. Evolução e situação atual do pólo PetrolinaJuazeiro: uma análise a partir dos indicadores socioeconômicos. 181 CONGRESSO DA SOBER "Conhecimentos para Agricultura do Futuro". 65, 2007, Londrina, Anais... Londrina, SOBER 2007.

SOUZA, Cláudio Luiz Gonçalves de. A teoria geral do comércio exterior: aspectos jurídicos e operacionais. Belo Horizonte: Líder, 2003.

VIEIRA, Aquiles. Teoria e prática cambial: exportação e importação. 3 ed. São Paulo: Aduaneiras, 2008.

Como citar este artigo (Formato ABNT):

FERREIRA, L.C.; SOUZA, H.B.B.; SANTANA, J.P.P. Desempenho das exportações do Pólo PetrolinaJuazeiro: Análise comparativa dos Resultados da Balança Comercial. Id on Line Revista Multidisciplinar e de Psicologia, Julho de 2016, vol.10, n.30, Supl. 3, p. 217-226. ISSN 1981-1179.

Recebido: 26/05/2016

Aceito: 01/06/2016 